\title{
Prize Structure and Information in Tournaments: Experimental Evidence
}

\section{Citation}

Freeman, Richard B., and Alexander M. Gelber. 2010. "Prize Structure and Information in Tournaments: Experimental Evidence." American Economic Journal: Applied Economics 2 (1) (January): 149-164. doi:10.1257/app.2.1.149.

\section{Published Version}

doi:10.1257/app.2.1.149

\section{Permanent link}

http://nrs.harvard.edu/urn-3:HUL.InstRepos:34310817

\section{Terms of Use}

This article was downloaded from Harvard University's DASH repository, and is made available under the terms and conditions applicable to Other Posted Material, as set forth at http:// nrs.harvard.edu/urn-3:HUL.InstRepos:dash.current.terms-of-use\#LAA

\section{Share Your Story}

The Harvard community has made this article openly available.

Please share how this access benefits you. Submit a story.

Accessibility 


\title{
Prize Structure and Information in Tournaments: Experimental Evidence ${ }^{\dagger}$
}

\author{
By Richard B. Freeman and Alexander M. Gelber**
}

\begin{abstract}
This paper examines behavior in a tournament in which we vary the tournament prize structure and the available information about participants' skill at the task of solving mazes. The number of solved mazes is lowest when payments are independent of performance; higher when a single, large prize is given; and highest when multiple, differentiated prizes are given. This result is strongest when we inform participants about the number of mazes they and others solved in a pre-tournament round. Some participants reported that they solved more mazes than they actually solved, and this misreporting also peaked with multiple differentiated prizes. (JEL D82)
\end{abstract}

\begin{abstract}
n tournament models, individuals respond to the opportunity to win prizes by assessing their chances of winning, the size of the prizes, and the cost of the effort in undertaking the tournament task. Models of tournament behavior predict that the aggregate effort of individuals in the tournament may be maximized by giving multiple prizes rather than a single prize, given a constant total tournament purse, heterogeneous skills, and a sufficiently convex cost for participants of putting forth effort (Benny Moldovanu and Aner Sela 2001, hereafter M\&S). Multiple prizes give more participants an incentive to try hard than a single large prize, which many participants may have little chance of winning. Prizes unrelated to output produce low effort as participants see no return to effort. However, there is little empirical work examining how behavior responds to differing prize structures or to information about participants' level of ability at the tournament task. Behavioral economics adds potential twists to traditional tournament theory, including suggesting that incentives may crowd out intrinsic motivation (Uri Gneezy and Aldo Rustichini 2000).

To assess behavior under different tournament prize structures and different information given to participants, we use a maze solving experiment that approximates important features of real world tournaments in which individuals with differing ability compete for prizes. We asked groups of six subjects to solve a set of

\footnotetext{
* Freeman: National Bureau of Economic Research, 1050 Massachusetts Ave., Cambridge, MA 02138 (e-mail: freeman@nber.org); Gelber: 1050 Massachusetts Ave., Cambridge, MA 02138 (e-mail: agelber@nber.org). We thank Judd Kessler, Dina Pomeranz, Alvin Roth, two anonymous referees, and seminar participants at Columbia University, Harvard University, and Uppsala University for suggestions. We thank Timur Akazhanov, Andrea Ellwood, Judd Kessler, and Julian Kolev for research assistance. Gelber acknowledges financial support from the National Institute on Aging, Grant Number T32-AG00186. All remaining errors are our own.

${ }^{\dagger}$ To comment on this article in the online discussion forum, or to view additional materials, visit the articles page at: http://www.aeaweb.org/articles.php?doi=10.1257/app.2.1.149.
} 
mazes in two rounds ${ }^{1}$ In Round 1 , we rewarded individuals by piece rates so that their reward depended only on their own performance. After the groups completed Round 1, we told participants in half of the groups about the distribution of mazes solved in Round 1 in their group, but we did not tell participants in the other half of the groups about the distribution in their groups. In Round 2, we gave three incentive treatments: a treatment that paid each person the same regardless of performance; a treatment with one large prize for the tournament winner; and a treatment with multiple prizes that increased with a participant's rank in the tournament. Total prize money was constant across the three incentive treatments. We measured the effects of the six treatments (three prize treatments in each information environment) on effort by measuring the number of mazes individuals solved.

Using the total number of mazes solved as a measure of output, we find that output is lowest when payments to participants are independent of performance; higher when only a single large prize is given; and highest when we give multiple differentiated prizes. While we cannot pinpoint the prize structure corresponding to the global maximum of output among the infinite number of possible allocations of a fixed tournament prize budget, our results demonstrate that multiple differentiated prizes in some form can produce higher output than either one single prize, or prizes unrelated to performance.

We also find that the information individuals have about how they and others performed in Round 1 of the experiment affected responses to the incentive conditions. The maximum under multiple prizes is strongest when we inform participants about the number of mazes they and others solved in Round 1. The differences in output among the conditions are, moreover, driven largely by the different responses to incentives of subjects with high or low maze solving ability, seemingly in response to the different marginal returns to effort in specific prize and information settings. When subjects knew the distribution of solved mazes from Round 1, those lower in the ability distribution solved more mazes with multiple prizes than they did with the single prize condition. By contrast, those higher in the ability distribution solved similar numbers of mazes with multiple prizes as they did under the single prize condition. Lower-ability subjects produced little when they knew they had little chance of winning a single prize through more effort. When subjects did not know the distribution of solved mazes from Round 1, the single and multiple prize treatments produced similar outcomes across the ability distribution, suggesting that when individuals did not know they ranked poorly in ability, they did not "give up" on winning the single prize.

The paper and pencil maze technology that we used in our experiment allowed subjects to falsely report unsolved mazes as solved. This serendipitously provides an independent test of the impact of incentives on behavior and a new approach to detecting cheating in the laboratory. As some form of cheating is widespread in many real world contexts (e.g., Brian A. Jacob and Steven D. Levitt 2003), our experiment provides an analog to a common setting. It relates to the multitask settings analyzed in the theory of incentives (Bengt Holmström and Paul Milgrom 1991), in

\footnotetext{
${ }^{1}$ Gneezy, Muriel Niederle, and Rustichini (2003) use maze solving to gauge the effort of subjects.
} 
which one of the tasks is reporting outcomes accurately. This could be relevant to a recent experience in the financial sector, in which increasingly high-powered incentives for executives seem to underlie increased malfeasance. In our experiment, the extent of misreporting varied with incentives in a similar way, as did the number of mazes solved.

The experiments closest to ours (Wieland Müller and Andrew Schotter 2004; Haig R. Nalbantian and Schotter 1997) examine how tournament prize structure affects effort, but not how information interacts with incentives or how incentives and information affect individuals with different ability levels 2 Niederle and Lise Vesterlund (2007) compare the decisions of men and women to enter a tournament. Ronald G. Ehrenberg and Michael L. Bognanno (1990) find that golf tournaments have incentive effects, but do not study the provision of information or which distribution of prizes maximizes effort. Other recent analyses connected to our work include Moldovanu, Sela, and Xianwen Shi (2007), who investigate the theory of tournaments in the presence of status concerns; Tor Eriksson, Anders Poulsen, and Marie-Claire Villeval (2008), who study the effect of feedback on performance under piece rates and tournaments; and Oriana Bandiera, Iwan Barankay, and Imran Rasul (2005) and Clive Bull, Schotter, and Keith Weigelt (1987), who compare piece rates and tournaments.

Section I describes the experiment. Section II presents the main results. Section III discusses results related to cheating in the experiment. Section IV concludes.

\section{The Experiment}

Our experiment recruited participants from a Harvard Business School Computer Lab for Experimental Research subject pool. We asked subjects to solve a set of mazes from Dave Phillips $(1988,1991)$ in a group with six participants. Groups gathered outside the room of the experiment and entered together, and subjects could observe that they were competing in a group with five others. The experiment had two rounds, each lasting for 15 minutes: a piece rate incentive session (Round 1) and a tournament session (Round 2). The maze packet used for Round 2 contained different mazes than those in the maze packet for Round 1. We presented the mazes to all subjects in the same order. The directions for each round and treatment are in the Appendix.

The participants were paid a $\$ 13$ show-up fee for participating in the experiment. In Round 1, we paid each subject an additional 20 cents per maze solved to motivate effort. We used the results under piece rates to identify their skill at solving mazes. At the end of Round 1, we told subjects in half of the groups the scores of all group members in Round 1. Since individuals knew their own score, this information allowed them to place themselves in the distribution and assess their chances of ranking high or low in Round 2. We refer to this treatment as "full information" because it gives subjects all the information that we have relevant to assessing their chances of winning in the ensuing tournament. In the other half of the experiments,

\footnotetext{
${ }^{2}$ Müller and Schotter (2004) find that some participants work hard in tournaments while others effectively drop out. Nalbantian and Schotter (1997) find that relative performance schemes outperform target-based schemes.
} 
which we refer to as "no information," we said nothing about how others performed. In all treatments, we announced the Round 2 prize structures after Round 1 was complete.

In Round 2, subjects competed in a tournament with three incentive treatments, each of which distributed $\$ 30$ in total prizes to each group. Our equal prize treatment gave each participant $\$ 5$ regardless of performance. The only incentive was the intrinsic desire to solve mazes or to do well relative to others. Our single prize treatment gave $\$ 30$ to the top scorer and nothing to anyone else. In the multiple prize condition, we gave multiple, differentiated prizes. Out of the many ways to do this, we chose one that gave incentives to persons in all parts of the distribution of mazesolving skill as reflected in their Round 1 maze performances. We gave the first prize winner $\$ 15$, the second prize winner $\$ 7$, the third prize winner $\$ 5$, the fourth prize winner $\$ 2$, and the fifth prize winner $\$ 1$. The experiment took approximately 50 minutes. Mean total earnings, including the show-up fee, Round 1 earnings, and Round 2 earnings, were $\$ 20.45$.

We presented the exercise to the subjects in paper and pencil form. We asked subjects to report the number of mazes they solved and told them that they had to solve them in the order they were presented in the packet. Initially, we did not consider that subjects might cheat, for example, by jumping over a line to complete a maze, or that some would misreport the mazes solved by counting the mazes they solved after they had skipped one as completed. When we checked the first sets of maze packets, we found discrepancies between the number of mazes subjects reported solving and the mazes that our rules would count as solved. We considered redoing the experiment in ways that would rule out such activity (for instance, by using a computer maze design) but realized that the potential for cheating serendipitously provides a second test of the effect of incentives on cheating in a tournament that differs greatly from the type of evidence in other experimental studies of cheating, such as studies on taxes ${ }^{3}$ The fact that cheating arose underscores the importance of examining its role in tournament settings and highlights a sometimes neglected aspect of incentive pay - the fact that incentives not only increase the reward to legitimate effort but also the reward to misreporting and cheating.

Incentives and Potential Behavior in the Experiment.-The performance of individuals in maze-solving depends on their ability and the effort they expend. The individual controls his or her effort. With total mazes solved in the group as the measure of output, the relation between output and the prize structure in a tournament setting depends on the distribution of participants' abilities, their perceived probability that increased effort will earn them a prize, and the values of the prizes. In the model of Edward P. Lazear and Sherwin Rosen (1981), participants have equal ability, and the optimal prize for winning mimics an optimal piece rate. In the M\&S model, participants have heterogeneous ability levels ${ }_{4}^{4}$ In this analysis, multiple prizes can

\footnotetext{
${ }^{3}$ Studies on cheating on taxes ask subjects to choose a level of cheating or shirking and explicitly state the reward or punishment scheme they will face, see James Alm, Gary H. McClelland, and William D. Schulze (1992).

${ }^{4}$ Vijay Krishna and John Morgan (1998) also study settings with multiple prizes.
} 
lead to greater output than a single prize because individuals with little chance of winning the single prize put in greater effort when they can win the second, third, or "nth" prize. The most able person may be less motivated by the presence of other prizes since the return to coming in first will be less than with a single prize, but less able contestants will be motivated by the rewards from doing better in the lower part of the prize distribution. $M \& S$ show that with a sufficiently convex cost of effort function, total effort is maximized in a setting with multiple prizes 5

The information structure of the tournament should affect behavior as well. In the M\&S model, individuals know the distribution function from which abilities are drawn. This enables those with high ability to assess their chances of winning. Assuming that individuals in the no information conditions have correct priors over the distribution of ability, then the M\&S information setting mimics the no information condition. Our experiment has a stronger information condition. In the full information case, individuals know the realized values of the abilities of other contestants. This approximates an alternative, and arguably more common, set of real world conditions in which participants have a better idea of their potential for winning than in the M\&S model, where they only know the distribution function from which competitors are drawn. This should affect the perceived probability that a given individual will win a prize. For instance, causing someone who is in a tournament with others with much higher Round 1 scores to put in low effort in the single prize condition as they perceive a low probability of winning the single prize.

\section{Findings}

Table 1 summarizes the means and standard deviations of subjects' scores in each treatment and both rounds of the experiment ${ }^{6}$ Since we randomly assigned individuals to treatments and gave the same Round 1 piece-rate incentive to all subjects, Round 1 scores should not differ noticeably among the groups. The Round 1 means show the different groups solved similar numbers of mazes. $F$-tests and pair-wise two-tailed Mann-Whitney $U$-tests confirm that there are no statistically different results in this round ${ }^{7}$ The Round 2 means show noticeable differences in scores among the treatment groups, which are significant by $F$-tests and pair-wise two-tailed Mann-Whitney $U$-tests. In the full information treatment, mean prizes solved rises from the equal prize to the multiple prize condition, and then fall with the one prize treatment. In the no information treatment, the lowest mean score is in the equal prize group, but the one prize group and the multiple prize group have

\footnotetext{
${ }^{5}$ This is M\&S (2001) Proposition 5, p. 549.

${ }^{6}$ We specified that the "mazes you solve that follow mazes you skipped will not be included in your total number of mazes," but some participants ignored this instruction and proceeded to solve mazes after failing to solve one, perhaps intending to go back and solve that one later. Thus, one measure of output is the number of mazes that subjects completed even when some solved mazes followed unsolved mazes. A second measure of output is the number of mazes a subject solved prior to skipping a maze. The first measure provides a potentially better indicator of the effort induced by the treatment, while the second follows our instructions. See Freeman and Gelber (2006) for an analysis of the second measure, as well as an analysis of the number of mazes solved in the second round, as reported by the subjects. We obtain results similar to those reported in this paper, which uses the number of mazes that subjects completed even when some solved mazes followed unsolved mazes. We exclude misreported mazes from the totals and examine them in Section III.

${ }^{7}$ For all three possible pairs of conditions, the pairwise test shows $p>0.40$.
} 
Table 1-Means and Standard Deviations of Individuals' MaZes Solved and Mazes Misreported, by Treatment

\begin{tabular}{|c|c|c|c|c|}
\hline \multirow[t]{2}{*}{ Treatment } & \multicolumn{2}{|c|}{$\begin{array}{l}\text { Mean }(\mathrm{SD}) \text { mazes } \\
\text { solved }\end{array}$} & \multicolumn{2}{|c|}{$\begin{array}{l}\text { Mean (SD) mazes } \\
\text { misreported }\end{array}$} \\
\hline & $\begin{array}{c}\text { Round } 1 \\
\text { (1) }\end{array}$ & $\begin{array}{c}\text { Round } 2 \\
\text { (2) }\end{array}$ & $\begin{array}{c}\text { Round } 1 \\
\text { (3) }\end{array}$ & $\begin{array}{c}\text { Round } 2 \\
\text { (4) }\end{array}$ \\
\hline \multicolumn{5}{|l|}{ Full information } \\
\hline Equal prize & $\begin{array}{c}12.65 \\
(4.86)\end{array}$ & $\begin{array}{l}15.55 \\
(7.08)\end{array}$ & $\begin{array}{c}0.09 \\
(0.33)\end{array}$ & $\begin{array}{c}0.18 \\
(0.58)\end{array}$ \\
\hline Multiple prize & $\begin{array}{c}12.40 \\
(4.44)\end{array}$ & $\begin{array}{l}18.56 \\
(6.87)\end{array}$ & $\begin{array}{c}0.13 \\
(0.54)\end{array}$ & $\begin{array}{c}0.51 \\
(1.44)\end{array}$ \\
\hline Single prize & $\begin{array}{l}11.74 \\
(5.24)\end{array}$ & $\begin{array}{c}16.10 \\
(7.88)\end{array}$ & $\begin{array}{c}0.19 \\
(1.20)\end{array}$ & $\begin{array}{c}0.46 \\
(1.15)\end{array}$ \\
\hline \multicolumn{5}{|l|}{ No information } \\
\hline Equal prize & $\begin{array}{l}12.46 \\
(4.68)\end{array}$ & $\begin{array}{c}12.88 \\
(5.62)\end{array}$ & $\begin{array}{c}0.09 \\
(0.33)\end{array}$ & $\begin{array}{c}0.13 \\
(0.49)\end{array}$ \\
\hline Multiple prize & $\begin{array}{l}11.91 \\
(5.27)\end{array}$ & $\begin{array}{c}16.36 \\
(7.89)\end{array}$ & $\begin{array}{c}0.17 \\
(0.84)\end{array}$ & $\begin{array}{c}0.32 \\
(1.62)\end{array}$ \\
\hline Single prize & $\begin{array}{c}12.31 \\
(5.05)\end{array}$ & $\begin{array}{c}16.53 \\
(7.38)\end{array}$ & $\begin{array}{c}0.12 \\
(0.39)\end{array}$ & $\begin{array}{c}0.23 \\
(0.68)\end{array}$ \\
\hline
\end{tabular}

Note: The sample size is 78 subjects for each of the 6 treatments shown, and 468 subjects total.

Source: Tabulated from the experiment described in the text.

similar mean outputs ${ }^{8}$ Comparing the full information and no information treatments, mean mazes solved are higher in the equal prize and multiple prize treatments under full information (15.55 and 18.56) than they are under no information (12.88 and 16.36, respectively), which is statistically significant at $p=0.02$ and $p$ $=0.07$, respectively. By contrast, the results under full information and under no information are not discernibly different for the single prize treatment (16.10 versus 16.53 , respectively; $p=0.58$ ).

\section{A. Regression Analysis}

To probe the Table 1 finding that multiple prizes produce higher output for the full information case, but not for the no information case, we use regression analysis for ease of presentation. We regressed the change in the number of mazes solved from Round 1 to Round 2 on a constant term and dummy variables for treatments:

$$
\left(R 2_{i}-R 1_{i}\right)=\beta_{0}+\mathbf{I}_{i} \beta+\varepsilon_{i},
$$

\footnotetext{
${ }^{8}$ In the no information condition, the two-tailed Mann-Whitney test for the single prize versus equal prize distribution shows $p=0.001$; multiple prize versus equal prize shows $p=0.008$; equal prize versus single prize shows $p=0.78$. In the full information condition, the two-tailed Mann-Whitney test for the single prize versus equal prize group shows $p=0.73$; multiple prize versus equal prize shows $p=0.008$; multiple prize versus single prize shows $p=0.04$.
} 
Table 2-Regression Coefficients and Standard ERrors for Determinants of Change in Mazes Solved From Round 1 to Round 2

\begin{tabular}{lccc}
\hline \hline & $\begin{array}{c}\text { All participants } \\
(1)\end{array}$ & $\begin{array}{c}\text { No info } \\
(2)\end{array}$ & $\begin{array}{c}\text { Full info } \\
(3)\end{array}$ \\
\hline EQUAL & - & - & - \\
MULTIPLE & 3.65 & 4.03 & 3.27 \\
& $(0.61)^{* * *}$ & $(0.79)^{* * *}$ & $(0.93)^{* * *}$ \\
SINGLE & 2.63 & 3.79 & 1.46 \\
& $(0.60)^{* * *}$ & $(0.74)^{* * *}$ & $(0.89)$ \\
FULL INFO & 1.44 & & \\
& $(0.52)^{* * *}$ & & \\
Constant & 0.94 & 0.42 & 2.90 \\
& $(0.45)^{* *}$ & $(0.51)$ & $(0.50)^{* * *}$ \\
$R^{2}$ & & & \\
Observations & 0.11 & 0.14 & 0.07 \\
\hline
\end{tabular}

Notes: The dependent variable is the change in the number of mazes solved from Round 1 to Round 2. EQUAL, MULTIPLE, and SINGLE represent dummies for the equal, multiple, and single prize conditions, respectively; FULL INFO represents a dummy for full information conditions. Robust standard errors, clustered by group, are in parentheses.

*** Significant at the 1 percent level.

** Significant at the 5 percent level.

* Significant at the 10 percent level.

where $\left(R 2_{i}-R 1_{i}\right)$ represents the change in score from Round 1 to Round $2, \mathbf{I}_{i}$ is a vector of dummies representing the incentive treatments, $\varepsilon$ is an error term, and $i$ is an individual indicator. Table 2 reports the estimated coefficients and standard errors relating the change in the number of mazes solved from Round 1 to Round 2 to the prize treatment, and, where relevant, a dummy variable for full information. The deleted group in all of the regressions is the equal prize treatment. Those who solved more mazes in Round 1 tended to solve more mazes in Round 2, with a correlation for all subjects of 0.74 , indicating that the Round 1 score is a reasonable indicator of the person's maze solving ability or, alternatively, of their intrinsic effort independent of incentives ${ }^{9}$ The coefficient on the full information treatment in column 1 is positive, indicating that, on average, the provision of information improved performance.

The key result from the Table 2 regressions is that output is highest under the multiple prize condition. The regression coefficients in column 1 for all treatments show a strong difference among the incentive treatments. The mazes solved by the equal prize group are substantially less than those solved by subjects in the other two treatments, and the multiple prize group has a higher number of mazes solved than the single prize group. When the sample is divided by information treatment in columns 2 and 3 , the difference in coefficients between the multiple prize and single prize treatment dummies is larger in the full information case (a difference of 1.81

\footnotetext{
${ }^{9}$ Note that in the experimental context we intend the term "ability" to refer explicitly to the Round 1 score. The key for our empirical analysis is that knowledge of other participants' Round 1 scores allows individuals to assess their chance of winning different prizes in Round 2.
} 
in column 3) than in the no information case (a difference of 0.24 in column 2) 10 This suggests that the prediction in the $M \& S$ model, that multiple prizes maximize output, is stronger under full information, as opposed to the setting they explored that did not examine the effect of the provision of such information.

To probe the robustness of this result, we investigated other specifications. We had data on the gender of subjects, and added a female dummy variable to the regression with little impact on the other coefficients ${ }^{11}$ We regressed the Round 2 score on the Round 1 score and the treatments. We entered the square of the Round 1 score along with the Round 1 score in the regressions. We excluded from the analysis data from those groups in which at least one person misreported a maze in Round 1. We introduced the Round 1 score of the highest scoring person in the group as an independent variable on the hypothesis that this could affect performances in the full information condition. We aggregated the mazes solved to the group level and regressed the change in total mazes solved by each group from Round 1 to Round 2 on the treatment dummies. As an alternative specification, we calculated changes in the mean number of mazes solved from Round 1 to Round 2 for each of the treatments and used this as the dependent variable. We investigated gender differences by estimating the models in Table 2 with the addition of a gender dummy and the interaction of that dummy with each of the five incentive treatments. None of the interactions was significant at the 5 percent level ${ }^{12}$

\section{B. Unpacking the Results}

At the heart of the analysis linking outcomes to incentive treatments is the notion that different prize structures should affect individuals differently depending on their maze-solving skills, assuming they are aware of their skills relative to others in the tournament. We investigate the impact of treatments on individuals in different positions in the maze-solving ability distribution by dividing the sample into those in the upper half of the distribution of mazes solved in Round 1 in the group in which they participated, and those in the lower half of the group.

Table 3 shows the estimated regression coefficients and standard errors from this analysis. The coefficients under the columns labeled top half and bottom half of the Round 1 distribution show different effects of the treatments. Under full information, in the bottom half, the single prize treatment is associated with a substantially smaller coefficient than the multiple prize treatment ( -0.12 and 4.22 , respectively).

\footnotetext{
${ }^{10}$ When we replicate Table 2 with the multiple prize dummy as the omitted category, we find the following: the dependent variable is significantly lower in the equal prize condition than the multiple prize condition $(p<0.001)$ when pooling both information settings and controlling for the dummy for the full information setting; output is insignificantly lower in the single prize condition than the multiple prize condition $(p=0.14)$ in this setting; in the no information setting, output is significantly lower in the equal prize condition than the multiple prize condition $(p<0.001)$ and insignificantly lower in the single prize condition than the multiple prize condition $(p>0.40)$; in the full information setting, output is significantly lower in the equal prize condition than the multiple prize condition $(p<0.001)$, and barely insignificantly lower in the single prize condition than the multiple prize condition $(p=0.10)$.

${ }^{11}$ Gneezy, Niederle, and Rustichini's (2003) findings suggest that women may perform differently in tournaments than men.

${ }^{12}$ See the Web Appendix. The same robustness checks also did not materially affect the Table 3 and Table 4 results.
} 
Table 3-Regression Coefficients and Standard Errors for Determinants of Change in Mazes SOLVED FROM Round 1 TO Round 2, By Position In Round 1

\begin{tabular}{|c|c|c|c|c|c|c|c|c|}
\hline & $\begin{array}{l}\text { Round } 1 \\
\text { top half, no } \\
\text { information } \\
\quad(1)\end{array}$ & $\begin{array}{l}\text { Round } 1 \text { top } \\
\text { half, full } \\
\text { information } \\
\text { (2) }\end{array}$ & $\begin{array}{c}\text { Round } 1 \\
\text { bottom } \\
\text { half, no } \\
\text { information } \\
\text { (3) }\end{array}$ & $\begin{array}{l}\text { Round } 1 \\
\text { bottom } \\
\text { half, full } \\
\text { information } \\
\text { (4) }\end{array}$ & $\begin{array}{c}\text { Round } 1 \\
\text { rank }=1 \text {, no } \\
\text { information } \\
(5)\end{array}$ & $\begin{array}{l}\text { Round } 1 \text { rank } \\
=1 \text {, full } \\
\text { information } \\
\text { (6) }\end{array}$ & $\begin{array}{c}\text { Round } 1 \\
\text { rank }=6, \text { no } \\
\text { information } \\
(7)\end{array}$ & $\begin{array}{l}\text { Round } 1 \text { rank } \\
=6 \text {, full } \\
\text { information } \\
\quad(8)\end{array}$ \\
\hline EQUAL & - & - & - & - & - & - & - & - \\
\hline MULTIPLE & $\begin{array}{l}5.70 \\
(1.03)^{* * *}\end{array}$ & $\begin{array}{l}2.45 \\
(1.31) *\end{array}$ & $\begin{array}{c}1.98 \\
(0.87)^{* *}\end{array}$ & $\begin{array}{l}4.22 \\
(1.06)^{* * *}\end{array}$ & $\begin{array}{l}5.89 \\
(2.16)^{* *}\end{array}$ & $\begin{array}{l}3.33 \\
(1.49)^{* *}\end{array}$ & $\begin{array}{l}1.67 \\
(0.92)^{*}\end{array}$ & $\begin{array}{l}3.83 \\
(1.54) * *\end{array}$ \\
\hline SINGLE & $\begin{array}{l}5.35 \\
(1.02)^{* * *}\end{array}$ & $\begin{array}{l}2.71 \\
(1.42)^{*}\end{array}$ & $\begin{array}{l}1.95 \\
(1.01) *\end{array}$ & $\begin{array}{c}-0.12 \\
(0.95)\end{array}$ & $\begin{array}{l}5.75 \\
(1.71) * * *\end{array}$ & $\begin{array}{l}3.26 \\
(1.65)^{*}\end{array}$ & $\begin{array}{l}4.31 \\
(1.29)^{* * * *}\end{array}$ & $\begin{array}{c}0.91 \\
(1.31)\end{array}$ \\
\hline Constant & $\begin{array}{c}-0.27 \\
(0.69)\end{array}$ & $\begin{array}{l}3.34 \\
(0.76) * * *\end{array}$ & $\begin{array}{c}1.32 \\
(0.60) * *\end{array}$ & $\begin{array}{l}2.41 \\
(0.68)^{* * * *}\end{array}$ & $\begin{array}{c}-0.69 \\
(1.48)\end{array}$ & $\begin{array}{l}3.27 \\
(0.90) * * *\end{array}$ & $\begin{array}{c}0.42 \\
(0.55)\end{array}$ & $\begin{array}{l}2.09 \\
(0.96) * *\end{array}$ \\
\hline$R^{2}$ & 0.22 & 0.05 & 0.05 & 0.20 & 0.22 & 0.09 & 0.29 & 0.19 \\
\hline Observations & 127 & 127 & 107 & 107 & 47 & 47 & 35 & 36 \\
\hline
\end{tabular}

Notes: The dependent variable is the change in the number of mazes solved from Round 1 to Round 2. EQUAL, MULTIPLE, and SINGLE represent dummies for the equal, multiple, and single prize conditions, respectively. Columns 1 and 2 display results for regressions including participants with Round 1 score ranked between 1 and 3 (inclusive); columns 3 and 4 display results for a regression in which the sample is all participants with Round 1 ranks 4 to 6 (inclusive). The sample size is larger for the top half than the bottom half because tied scores were assigned the same rank; results are similar with other ways of assigning ties. This is also the reason that the sample size is larger for those ranked 1 in Round 1 (columns 5 and 6) than those ranked 6 in Round 1 (columns 7 and 8 ). Odd numbered columns restrict the sample to no information conditions, and even numbered to full information conditions. Robust standard errors, clustered by group, are in parentheses.

*** Significant at the 1 percent level.

** Significant at the 5 percent level.

* Significant at the 10 percent level.

By contrast, in the top half, under full information, there is a slightly larger coefficient on the single prize treatment than there is on the multiple prize treatment $(2.71$ and 2.45, respectively). Knowledge of their low chance of winning the single prize seemingly discouraged people in the lower half of the distribution while encouraging those in the upper half. As a result, the maximum associated with the multiple prize condition is pronounced for the bottom half of the distribution, but absent from the top half of the distribution.

The results for the no information treatment are different. Individuals in the top half of the distribution score more under single-prize and multiple-prize incentives than individuals in the equal prize group. There is little evidence of a maximum under multiple prizes in the bottom half of the distribution as the score for the multiple prize treatment somewhat exceeds that for the equal prize, and just exceeds that for the single prize treatment. Provision of information has its biggest effect on individuals in the bottom half of the Round 1 distribution of maze-solving scores. Knowledge that they have little chance of winning a single, large prize appears to discourage them.

One other pattern in the data requires explanation. This is the higher scores of subjects in the full information equal prize group compared to the scores of subjects in the no information equal prize (deleted) group. The unadjusted mean differences in Table 1 are significantly different in the two conditions, and a regression controlling for Round 1 score also shows a significant difference. Since subjects gained no 
money from solving more mazes in the equal prize treatment, pecuniary incentives cannot account for this result. One possible explanation is that individuals at the low end realized they could do better in the full information treatment and tried harder due to intrinsic competitive motivation. Niederle and Vesterlund's (2007) finding that men respond more competitively to tournaments than women is consistent with the hypothesis that men are more subject to an intrinsic motivation effect. Looking at our data by gender, we find a pattern consistent with this hypothesis. In the equal prize treatment, men raised their scores more in the full information case than women did. In the equal prize treatment, the mean Round 1 to Round 2 gain in scores was 2.16 more in full information than in no information for men, whereas it was 1.30 more for women $(p<0.05)$.

As a final check on the differential response to the treatments of subjects in different positions in the maze-scoring distribution, we report, in columns 5-8 of Table 3 , the coefficients on treatments for the person who scored highest in their group in Round 1 and the person who scored lowest in their group in Round 1. In both the full information and no information cases, the individuals who did best in Round 1 increased their scores more in the multiple prize and single prize treatment than in the equal prize treatment, while those who did the worst in Round 1 improved their scores most in the full information multiple prize treatment. Comparing the difference in scores between full information and no information, those with high scores increased their scores from the no information to the full information treatment by the greatest amount in the equal prize case and the smallest amount in the multiple prize case. By contrast, the lowest scoring subjects in Round 1 increased their scores most from no information to full information in the multiple prize treatment, presumably because they realized that they had a chance to win some reward from greater effort. By contrast, they reduced their scores from the no information to the full information treatments in the single prize treatment, presumably because they realized they had little chance to win the single prize 13

\section{Incentives and Misreporting/Cheating}

By asking subjects to solve paper mazes in which the subjects use a pencil to draw lines from the beginning of the maze to the end, we created another test of how incentives affect behavior by opening the door for misreporting or cheating ${ }^{14}$ Our instructions told subjects to solve the mazes in the order that they appeared in their packets and that "any mazes you solve that follow a maze you skipped will not be counted in your total number of mazes..." We also told subjects that "solving a maze means drawing a continuous line from the place marked 'Start' to the place marked

\footnotetext{
${ }^{13}$ In some situations, the top score from a group may matter rather than the sum of all the scores. Using a group's top score to measure output, we still find that multiple prizes produce the greatest output, though the difference between multiple prizes and the single prize is smaller than in the comparable regression in Table 3. In other situations, the performance of the lower scoring individual may matter most. Under full information, the multiple prize condition gives markedly higher results than the other treatments, due to the incentives that multiple prizes give in the lowest part of the distribution. See Freeman and Gelber (2006).

${ }^{14}$ Breaking the rules of a maze solving experiment is not possible when subjects solve mazes on the computer, as in previous literature.
} 
'Finish,' without crossing any of the walls of the maze with your line.' Finally, we asked subjects to report the number of mazes they solved according to those rules.

Reviewing the packets of solved mazes after the first set of experiments, we discovered that subjects sometimes reported more mazes solved than met our rules. The vast majority of misreporting consisted of subjects starting a maze but not finishing it, then moving on to subsequent mazes in their maze packet, and reporting the subsequent mazes in their total number solved. There were three other less frequent forms of misreporting. Some subjects completely skipped a maze, yet reported subsequent mazes they solved in the number solved. Some subjects crossed one of the walls of a maze with a line, yet counted this maze among the total number they solved. And, some subjects reported a different total number solved than the total they actually solved. The results we report include all four types of cheating, but all types of cheating show similar patterns across treatments 15

The final two columns of Table 1 present summary statistics on the frequency of such misreporting. In Round 1, the largest number of misreports occurred under the full information multiple prize treatment. But $F$ - or $c h i$-squared tests of the effect of the treatments show no statistically significant difference among the groups in this round. By contrast, the means for Round 2 show that misreporting is higher in the full information treatment than in the no information treatment $(p=0.006)$. This is presumably because people in full information have a better idea of how they might improve their chances of gaining a prize by misreporting. In both the full information case and the no information case, the mean number of misreports is several times larger in the multiple-prize and single-prize treatments compared with the equal prize treatment. In both the full information and no information setting, the largest number of misreports is associated with the multiple prize condition. Thus, incentives seem to work in a similar way in misreporting as they do in genuine maze solving.

Table 4 presents the coefficients and standard errors from a Poisson regression in which the dependent variable is the number of misreports in Round 2. We use the Poisson model because misreports are a relatively infrequent event. ${ }^{16}$ In the full information case, the regressions show that misreporting is greatest in the multiple prize setting, second highest in the single prize setting, and lowest in the equalprize condition (column 1). Looking at behavior among subjects in the upper and lower halves of the distribution of maze-solving in Round 1, the regression coefficients in columns 2 and 3 show that this result is due to much higher misreporting by individuals in the multiple- and single-prize treatments than those in the equal

\footnotetext{
${ }^{15}$ Some of the misreporting may have represented unintentional mistakes, but the empirical results show that misreporting varies strongly with incentives, and this cannot be reconciled with random mistakes. With random mistakes, we would expect to find occasional underreporting, but we did not find underreporting. Moreover, it seems reasonable that if one starts a maze, does not finish it, but reports this maze as solved in one's total number of mazes, then this is intentional. When we limit the measure of cheating to only those misreports that involved this form of misreporting, we find similar patterns to those reported.

${ }^{16}$ Negative binomial regressions show similar results to the Poisson regressions. A linear model shows differences among the treatments with similar magnitudes to those implied by the unadjusted differences shown in Table 1. Adding individuals' Round 1 score to the model does not appreciably change the results. Since the Poisson specification involves maximizing a nonlinear likelihood function, we would face an incidental parameters problem if we first-differenced the dependent variable as in Tables 2 and 3. Thus, we control for Round 1 fudges as an independent variable.
} 
Table 4-Poisson Regression Coefficients and Standard Errors for Determinants of Total Number of MaZes Misreported in Round 2

\begin{tabular}{|c|c|c|c|c|c|c|}
\hline & \multicolumn{3}{|c|}{ Full information } & \multicolumn{3}{|c|}{ No information } \\
\hline & $\begin{array}{c}\text { All subjects } \\
\text { (1) }\end{array}$ & $\begin{array}{l}\text { Top half } \\
\text { (2) }\end{array}$ & $\begin{array}{l}\text { Bottom half } \\
\text { (3) }\end{array}$ & $\begin{array}{l}\text { All subjects } \\
\text { (4) }\end{array}$ & $\begin{array}{l}\text { Top half } \\
(5)\end{array}$ & $\begin{array}{l}\text { Bottom half } \\
\text { (6) }\end{array}$ \\
\hline EQUAL & - & - & - & - & - & - \\
\hline MULTIPLE & $\begin{array}{l}1.01 \\
(0.41) * *\end{array}$ & $\begin{array}{l}1.29 \\
(0.57) * *\end{array}$ & $\begin{array}{l}0.94 \\
(0.49)^{*}\end{array}$ & $\begin{array}{c}-0.21 \\
(0.58)\end{array}$ & $\begin{array}{c}0.33 \\
(0.79)\end{array}$ & $\begin{array}{c}-0.50 \\
(0.88)\end{array}$ \\
\hline SINGLE & $\begin{array}{c}0.50 \\
(0.43)\end{array}$ & $\begin{array}{l}1.75 \\
(0.55)^{* * *}\end{array}$ & $\begin{array}{c}-0.71 \\
(0.82)\end{array}$ & $\begin{array}{c}0.55 \\
(0.44)\end{array}$ & $\begin{array}{c}0.61 \\
(0.76)\end{array}$ & $\begin{array}{c}0.45 \\
(0.53)\end{array}$ \\
\hline $\begin{array}{l}\text { Mazes misreported in } \\
\text { Round } 1\end{array}$ & $\begin{array}{l}0.38 \\
(0.05) * * *\end{array}$ & $\begin{array}{l}1.87 \\
(0.87)^{* *}\end{array}$ & $\begin{array}{l}0.46 \\
(0.09)^{* * *}\end{array}$ & $\begin{array}{l}0.74 \\
(0.07)^{* * *}\end{array}$ & $\begin{array}{l}0.85 \\
(0.96)\end{array}$ & $\begin{array}{l}0.72 \\
(0.11) * * *\end{array}$ \\
\hline Constant & $\begin{array}{l}-1.76 \\
(0.35) * * *\end{array}$ & $\begin{array}{l}-2.56 \\
(0.50) * * *\end{array}$ & $\begin{array}{l}-1.39 \\
(0.41) * * *\end{array}$ & $\begin{array}{c}-2.16 \\
(0.33)\end{array}$ & $\begin{array}{l}-2.75 \\
(0.70) * * *\end{array}$ & $\begin{array}{l}-1.75 \\
(0.41)^{* * *}\end{array}$ \\
\hline Observations & 234 & 127 & 107 & 234 & 127 & 107 \\
\hline Log pseudo-likelihood & -177.52 & -79.77 & -88.16 & -102.20 & -40.41 & -59.31 \\
\hline
\end{tabular}

Notes: The number of mazes misreported in Round 2 is regressed on dummies for the incentive conditions, the number of mazes misreported in Round 1, and a constant term. Columns 1 and 4 display results for a regression in which the sample is all participants; columns 2 and 5 display results for a regression in which the sample is all participants with Round 1 ranks 1 to 3 (inclusive); columns 3 and 6 display results for a regression in which the sample is all participants with Round 1 ranks 4 to 6 (inclusive). The sample size is larger for the top half than the bottom half because tied scores were assigned the same rank; results are similar with other ways of assigning ties. Robust standard errors, clustered by group, are in parentheses.

$* * *$ Significant at the 1 percent level.

** Significant at the 5 percent level.

* Significant at the 10 percent level.

prize treatment for those at the upper half of the distribution and a low number of misreports among individuals in the single-prize treatment in the bottom half of the distribution. When a lot of prize money is at stake, and participants know that they have a chance of winning, they are more likely to cheat to win. By contrast, there are no statistically significant differences in misreporting in the no information treatment. Moreover, the percentage difference in cheating across treatments is greater than the percentage differences across treatments in output ${ }^{17}$

\section{Conclusion}

This paper has examined the impact of tournament prize structure and provision of information about individuals' skill. The first round of the experiment gave all participants the same piece -ate incentive. The second round varied the incentives and information about the number of mazes solved by participants in the pre-tournament round. The experiment found that multiple prizes elicited more effort than a single prize or equal prizes. It is worth noting that the most unequal compensation system-giving only one large prize-did not always maximize aggregate effort. The most equal system, giving multiple prizes of equal value, also did not always

\footnotetext{
${ }^{17}$ This is consistent with Jacob and Levitt (2003), who find that cheating is extremely sensitive to the incentives to cheat.
} 
maximize aggregate effort. In the full information setting, it was a tournament prize structure in between these two extremes, giving relatively strong incentives to individuals throughout the distribution of ability, that maximized aggregate effort. This finding is consistent with the spirit of M\&S's analysis that multiple prizes maximize total effort. The evidence that the multiple prize effect is stronger under full information than under no information goes beyond their model because our full information treatment gives individuals information about the realized abilities of their competitors.

The results were strongest for individuals in the bottom half of the distribution, where output fell in the single-prize treatment relative to the multiple-prize treatment. When individuals are aware of their ability relative to others, a single, large prize does not motivate those at the bottom of the ability distribution, who have little chance of winning it. They put forth more effort when they have a better chance to win more in a multiple prize setting. This suggests that theories of tournament behavior should focus more on the provision of information than they currently do. Our results suggest that under some prize structures it may benefit an employer or tournament creator to provide full information about performance while in other cases it may not. The evidence that participants solved more mazes in the full information no inequality treatment than in the no information no inequality treatment suggests that behavior is affected by intrinsic motivation or some other psychological factor not typically examined in incentive models. This points to potentially fruitful lines of further theoretical and empirical work.

Finally, our experimental design offers a new way to detect cheating without alerting participants to the fact that their cheating will be examined by the experimenters. The finding that the information and incentive structure affected cheating in a similar manner to output raises important issues about analyses of incentive pay. The importance of cheating in our experiment suggests the need to model multi-task moral hazard or other features of cheating in a tournament setting. Economic analyses of executive compensation, in particular, have typically not focused on the possibility that incentives not only motivate productive effort but also motivate cheating of various forms. It has not escaped our notice that the cheating behavior uncovered in our experiment has parallels in the behavior that contributed to the financial meltdown of Wall Street of 2008. The fact that relatively modest incentives generated as much misreporting as we uncovered raises important questions about the responsiveness of misreporting and cheating to the much larger stakes outside the laboratory. Tournament models that put greater stress on the dual effect of incentives may offer greater guidance to firms and policymakers concerned by the possible impact of compensation structure on malfeasance.

\section{APPENDIX}

\section{Instructions (Round 1)}

Each of you has been given a packet of mazes. Please do not turn this packet over until the room monitor says to start. Please write your name on the back of this packet. 
"Solving" a maze means that you draw a continuous line from the place on the maze marked "Start" to the place marked "Finish," without crossing any of the walls of the maze with your line. All of the mazes in your packets have solutions. Please begin working on the first maze in the packet and work through the packet in order. Begin working on a new maze only when you have finished solving the maze that preceded it in the packet. If you work out of order and skip at least one maze, you will not be given credit in your total number of mazes for mazes you solved that follow the maze you skipped. We will check the accuracy of your solutions to the mazes.

You will have 15 minutes to solve as many mazes as you can. You will receive 20 cents for each maze you solve (on top of your guaranteed payment of $\$ 13$ for showing up at the experiment). If, over the course of this session, you make stray lines on your sheet that do not lead from the start of the maze to the finish, you are not required to erase these lines during the 15-minute session itself, but you may erase them if you wish to do so.

Each of you has received a packet of mazes that is identical to the packet each other participant has received. It will not be announced at any point in the experiment which participant received which score in this session.

Please do not talk to other participants while you are solving the mazes. Also, please do not talk in the break between solving mazes in the packet you have been given and solving mazes in the next packet. Please turn off your cellular phones before the experiment begins.

If you have a question about these directions, please raise your hand now.

\section{Instructions (read by experimenter after Round 1):}

Please count the number of mazes that you solved correctly in the first session, and please write this number on the front of your maze packet with a circle around it. If you skipped a maze, please do not include subsequent mazes solved in the total you report. Please raise your hand when you have finished this, so that the room monitor can collect your packet from you.

Only in the "Full Information" Treatments, Read: An experimenter will now give to each of you a list of the number of mazes each member of your group solved in the first session. The number that you solved has been circled, and the numbers that the other members of your group solved have not been circled.

\section{Instructions (Round 2):}

Each of you has been given a second packet of mazes. Please write your name on the back of this packet. Please do not turn this packet over and begin working on it until the room monitor says to start.

"Solving" a maze means that you draw a continuous line from the place on the maze marked "Start" to the place marked "Finish," without crossing any of the walls of the maze with your line. All of the mazes in your packets have solutions. Please begin working on the first maze in the packet and work through the packet in order. Begin working on a new maze only when you have finished solving the maze that preceded it in the packet. If you work out of order and skip at least one maze, you will not be given credit in your total number of mazes for mazes you solved that 
follow the maze you skipped. We will check the accuracy of your solutions to the mazes.

You will have 15 minutes to solve mazes in your packet.

\section{For "Equal prize" Treatments, read:}

In this session, which is the final session of the experiment, you will receive $\mathbf{\$ 5}$, regardless of how many mazes you solve.

\section{For "Multiple Prize" Treatments, read:}

In this session, which is the final session of the experiment, you will be paid based on how many mazes you solve, in comparison with how many mazes the other participants solve. If you solve the most mazes in this session out of the members of this group, you will receive $\mathbf{\$ 1 5}$, in addition to your show-up fee, plus what you earned in the first session. If you solve the second-most mazes in this session out of the members of this group, you will receive $\$ \mathbf{7}$, in addition to your show-up fee, plus what you earned in the first session. If you solve the third-most mazes in this session out of the members of this group, you will receive $\mathbf{\$ 5}$, in addition to your show-up fee, plus what you earned in the first session. If you solve the fourth-most mazes in this session out of the members of this group, you will receive $\mathbf{\$ 2}$, in addition to your show-up fee, plus what you earned in the first session. If you solve the fifth-most mazes in this session out of the members of this group, you will receive $\$ \mathbf{1}$, in addition to your show-up fee, plus what you earned in the first session. If you solve the sixth-most mazes in this session out of the members of this group, you will receive only your show-up fee, plus what you earned in the first session.

Your payment from this session (the second session) will be based only on how many mazes you solve in the second session. The number you solved in the first session is irrelevant to the payment you receive in this session.

\section{For "Single Prize" Treatments, read:}

You will have 15 minutes to solve mazes in your packet. In this session, which is the final session of the experiment, you will be paid based on how many mazes you solve, in comparison with how many mazes the other participants solve. If you solve the most mazes in this session out of the members of this group, you will receive \$30, in addition to your show-up fee, plus what you earned in the first session. Everyone else will receive only their show-up fee, plus what they earned in the previous session.

Your payment from this session (the second session) will be based only on how many mazes you solve in the second session. The number you solved in the first session is irrelevant to the payment you receive in this session.

\section{In all treatments, read:}

Each of you has received a packet of mazes that is identical to the packet each other participant has received. It will not be announced at any point in the experiment which participant received which score in this session. Please do not talk while you are solving the mazes.

If you have a question about these directions, please raise your hand now. 


\section{REFERENCES}

Alm, James, Gary H. McClelland, and William D. Schulze. 1992. "Why Do People Pay Taxes?” Journal of Public Economics, 48(1): 21-38.

- Bandiera, Oriana, Iwan Barankay, and Imran Rasul. 2005. "Social Preferences and the Response to Incentives: Evidence from Personnel Data." Quarterly Journal of Economics, 120(3): 917-62.

Bull, Clive, Andrew Schotter, and Keith Weigelt. 1987. "Tournaments and Piece Rates: An Experimental Study.” Journal of Political Economy, 95(1): 1-33.

-Ehrenberg, Ronald G., and Michael L. Bognanno. 1990. "Do Tournaments Have Incentive Effects?" Journal of Political Economy, 98(6): 1307-24.

Eriksson, Tor, Anders Poulsen, and Marie-Claire Villeval. 2008. "Feedback and Incentives: Experimental Evidence.” Institute for the Study of Labor (IZA) Discussion Paper 3440.

Freeman, Richard B., and Alexander M. Gelber. 2006. "Optimal Inequality/Optimal Incentives: Evidence from a Tournament.” National Bureau of Economic Research Working Paper 12588.

Gneezy, Uri, Muriel Niederle, and Aldo Rustichini. 2003. "Performance in Competitive Environments: Gender Differences." Quarterly Journal of Economics, 118(3): 1049-74.

- Gneezy, Uri, and Aldo Rustichini. 2000. "Pay Enough or Don't Pay at All." Quarterly Journal of Economics, 115(3): 791-810.

Holmström, Bengt, and Paul Milgrom. 1991. "Multitask Principal-Agent Analyses: Incentive Contracts, Asset Ownership, and Job Design." Journal of Law, Economics, and Organization, 7 (Special Issue): $24-52$.

Jacob, Brian A., and Steven D. Levitt. 2003. "Rotten Apples: An Investigation of the Prevalence and Predictors of Teacher Cheating." Quarterly Journal of Economics, 118(3): 843-77.

Krishna, Vijay, and John Morgan. 1998. "The Winner-Take-All Principle in Small Tournaments." In Advances in Applied Microeconomics, Vol. 7, ed. Michael R. Baye, 841-64. Stamford, CT: JAI Press.

- Lazear, Edward P., and Sherwin Rosen. 1981. "Rank-Order Tournaments as Optimum Labor Contracts." Journal of Political Economy, 89(5): 841-64.

Moldovanu, Benny, and Aner Sela. 2001. "The Optimal Allocation of Prizes in Contests." American Economic Review, 91(3): 542-58.

-Moldovanu, Benny, Aner Sela, and Xianwen Shi. 2007. "Contests for Status." Journal of Political Economy, 115(2): 338-63.

Müller, Wieland, and Andrew Schotter. 2004. "Workaholics and Dropouts in Optimal Organizations." New York University Center for Experimental Social Science Working Paper 22.

Nalbantian, Haig R., and Andrew Schotter. 1997. "Productivity under Group Incentives: An Experimental Study." American Economic Review, 87(3): 314-41.

- Niederle, Muriel, and Lise Vesterlund. 2007. "Do Women Shy Away from Competition? Do Men Compete Too Much?" Quarterly Journal of Economics, 122(3): 1067-1101.

Phillips, Dave. 1988. Space Age Mazes. New York: Dover.

Phillips, Dave. 1991. Animal Mazes. New York: Dover. 